\title{
Review
}

\section{Management of heart failure with reduced ejection fraction: challenges in patients with atrial fibrillation, renal disease and in the elderly}

\author{
Yotam Kolben $^{1, \dagger}$, Asa Kessler ${ }^{1, \dagger}$, Gal Puris ${ }^{2}$, Dean Nachman ${ }^{3}$, Paulino Alvarez ${ }^{4}$, \\ Alexandros Briasoulis ${ }^{5,6}$, Rabea Asleh ${ }^{3, *}$ \\ ${ }^{1}$ Department of Internal Medicine, Hadassah Medical Center and Faculty of Medicine, Hebrew University of Jerusalem, 91905 Jerusalem, Israel \\ ${ }^{2}$ Department of Medical Research, Hadassah Medical Center and Faculty of Medicine, Hebrew University of Jerusalem, 91905 Jerusalem, Israel \\ ${ }^{3}$ The heart institute, Hadassah Medical Center and Faculty of Medicine, Hebrew University of Jerusalem, 91905 Jerusalem, Israel \\ ${ }^{4}$ Cleveland Clinic Foundation, Cleveland, OH 44195, USA \\ ${ }^{5}$ Department of Clinical Therapeutics, Medical School, National Kapodistrian University of Athens, 10679 Athens, Greece \\ ${ }^{6}$ Division of Cardiology, University of Iowa, Iowa City, IA 52242, USA \\ *Correspondence: rasleh@hadassah.org.il (Rabea Alseh) \\ $\dagger$ These authors contributed equally. \\ Academic Editors: Matteo Cameli and Alberto Palazzuoli \\ Submitted: 5 October 2021 Revised: 6 November 2021 Accepted: 23 November 2021 Published: 14 January 2022
}

\begin{abstract}
Heart failure with reduced ejection fraction (HFrEF) is an increasing global pandemic affecting more than 30 million individuals worldwide. Importantly, HFrEF is frequently accompanied by the presence of cardiac and non-cardiac comorbidities that may greatly influence the management and prognosis of the disease. In this review article, we will focus on three important comorbidities in HFrEF; atrial fibrillation (AF), advanced renal disease, and elderly, which all have a paramount impact on progression of the disease, management strategies, and response to therapy. AF is very common in HFrEF and shares many risk factors. AF aggravates heart failure and contributes to HFrelated adverse clinical outcomes; hence it requires special consideration in HFrEF management. The kidney function is largely affected by the reduced cardiac output developed in the setting of HFrEF, and the neurohormonal feedback effects create a complex interplay that pose challenges in the management of HFrEF when renal function is significantly impaired. Cardiorenal syndrome is a challenging sequela with increased morbidity and mortality thereby reflecting the delicate and complex balance between the heart and the kidney in HFrEF and renal failure conditions. Furthermore, patients with advanced renal failure have poor prognosis in the presence of HFrEF with limited treatment options. Finally, aging and frailty are important factors that influence treatment strategies in HFrEF with greater emphasis on tolerability and safety of the various HFrEF therapies in elderly individuals.
\end{abstract}

Keywords: Heart failure with reduced ejection fraction; Atrial fibrillation; Advanced renal disease; Elderly; Management

\section{Introduction}

The prevalence of heart failure (HF) is estimated to be $1-2 \%$ in Europe and the US [1]. The disease burden has been described widely, and for decades it has been considered a global epidemic [2]. The most used categorization of different types of HF is based on the ejection fraction (EF). HF with preserved $\mathrm{EF}$ (HFpEF), defined as $\mathrm{EF} \geq 50 \%$, is a medical condition with uprising awareness and limited treatment options, and it is a considerably different disease from $\mathrm{HF}$ with reduced $\mathrm{EF}$ (HFrEF, $\mathrm{EF}<40 \%$ ) [3]. The last group of $\mathrm{HF}$ is characterized by $40 \%<\mathrm{EF}<49 \%$ and currently referred to as HF with mildly reduced EF (HFmrEF) [4]. Each category of HF is unique in terms of risk factors, pathophysiology, and treatment options [4].

Several comorbidities and medical conditions commonly arise with or secondary to HFrEF, complicating its management and necessitating special clinical attention [5]. In this review, we chose to focus on three comorbidities: atrial fibrillation (AF), advanced renal disease, and elderly patients, which often coexist but many times are overlooked. Those comorbidities directly affect the opti- mal treatment for patients with HFrEF, as some treatments are preferred, and some are contraindicated. Many trials have excluded these populations, and the consequence is that minimal treatment options are offered in the standard guidelines to these challenging populations. Although other comorbidities exist, the complexity of the pathogenesis and approach in these three groups require special attention. AF has shared risk factors with HFrEF, and when arise together, distinct caution should be undertaken in its management due to specific contraindications, eventually the prognosis is also affected [6]. Patients with advanced renal disease also share predisposing conditions with HFrEF patients, which may precipitate and complicate the cardiac condition [7]. Elderly patients, usually neglected in most clinical trials [8], also need special attention due to fragility, comorbidities, and limited data regarding treatments at advanced age. This review will focus on these three sub-groups of HFrEF patients to emphasize the importance of special considerations regarding optimal management options for these cohorts in the presence of limited data and numerous challenges. 


\section{Heart failure with reduced ejection in patient with atrial fibrillation}

The association between $\mathrm{AF}$ and $\mathrm{HF}$ was recognized over 70 years ago [9]. It is estimated that by 2030 , the incidence of $\mathrm{AF}$ and $\mathrm{HF}$ in the US population will be around 12 million and 8 million, respectively [10,11]. Both conditions are prevalent individually, and they often co-exist due to overlapping risk factors such as hypertension, diabetes mellitus, ischemic heart disease, and valvular disease, but they also have mutual etiological, practical, and prognostic impact [12]. Previous data suggested that the prevalence of $\mathrm{AF}$ among patients with left ventricular dysfunction is $6-35 \%$, correlating with the severity of cardiac dysfunction $[13,14]$. However, analysis of the data from the Framingham Heart Study showed that among 1166 participants with a new diagnosis of HF, 57\% had AF [12]. HFpEF diagnosis had a trend for a stronger association with AF than HFrEF (hazard ratio (HR) 2.34 and 1.32 respectively, $p=0.06$ ). Among 1737 patients with a new AF diagnosis, 37\% had $\mathrm{HF}$ [12]. The prevalence of AF is rising in parallel with the severity of the HF, starting with $5 \%$ in patients with New-York heart association (NYHA) functional class I, up to $50 \%$ with NYHA IV [15].

Other than shared risk factors, both conditions precipitate each other. HF model in dogs showed extensive fibrosis in the atrium, promoting the formation of AF [16]. In a similar model, angiotensin-converting enzyme (ACE) inhibition prevented increased tissue angiotensin II, cellular apoptosis, and tissue fibrosis [17], suggesting neurohormonal changes similar to HF. There is a growing evidence that renin-angiotensin system (RAS) blockade in some patients might reduce the occurrence of AF [18]. Dogs with $\mathrm{HF}$ also demonstrated discrete changes in atrial action potential properties and currents, which are not seen in the induction of chronic atrial tachycardia [19]. Autopsies from hearts of dilated and hypertrophied cardiomyopathy showed a significantly greater extent of fibrosis in the left atrium, comparing patients after MI $(p<0.01)$ [20]. This data suggests that HF may precipitate AF in different mechanisms.

AF may worsen HF in several ways. Shorter diastolic filling time due to elevated heart rate and the loss of the atrial contraction may reduce cardiac output. In addition, $\mathrm{AF}$ is the most common cause of tachycardia-induced cardiomyopathy [21]. Restoration of sinus rhythm improves cardiac output, exercise capacity, and maximal oxygen consumption [22].

Retrospective data suggest that HF patients with concomitant AF have increased mortality risk compared with HF patients without AF (relative risk (RR) 1.34, $p=0.002$ ) [13]. Among patients with acute myocardial infarct (AMI) complicated by HF, AF was associated with greater longterm mortality [23]. A meta-analysis showed that AF was associated with all-cause mortality in both randomized (odds ratio (OR) 1.4, $p<0.0001$ ) and observational (OR

\section{$1.14, p<0.05)$ studies of HF patients [24].}

Although the high prevalence of joint conditions, treatment options for $\mathrm{AF}$ in patients with $\mathrm{HF}$ are limited. Maintaining a resting HR below $110 \mathrm{bpm}$ is recommended, although not categorically proven [25]. The rate versus rhythm control debate is still ongoing, with no clear winner. The AF-CHF (atrial fibrillation and congestive heart failure) trial compared both strategies and showed no difference in mortality, stroke, or worsening HF [26]. Regarding rate-control of $\mathrm{AF}$, calcium channel blockers are not recommended in HFrEF, and digoxin may be associated with increased mortality [27]. Beta-blockers, which represent the mainstay of $\mathrm{HF}$ and $\mathrm{AF}$ treatment, have yet to show improved outcomes when the conditions are combined [28]. Most rhythm-control drugs used to restore and maintain sinus rhythm are contraindicated in HF. The proarrhythmic effect of class I antiarrhythmic medications leaves some class III drugs, along with their prevalent adverse reactions, almost as the sole option [29]. SGLT-2 inhibitors are gaining momentum recently in the cardiovascular field. The DECLARE-TIMI 58 (Dapagliflozin Effect on Cardiovascular Events-Thrombolysis in Myocardial Infarction 58) trial studied the effect of dapagliflozin in patients with type 2 diabetes mellitus and either atherosclerotic risk factors or known atherosclerotic disease. It showed that dapagliflozin decreased the incidence of AF (and Atrial flutter) during follow-up, as compared to placebo (HR 0.81, $p=0.009$ ) [30]. A systematic review of 31 articles including a total of 75,279 patients was recently published. This analysis showed that treatment with SGLT-2 inhibitors resulted in a $25 \%$ relative risk reduction in serious $\mathrm{AF}$ events and a similar reduction in total $\mathrm{AF}$ events [31].

The CASTLE-AF (Catheter Ablation versus Standard conventional Treatment in patients with Left ventricular dysfunction and Atrial Fibrillation) trial showed that treatment with catheter ablation for AF was superior to optimal medical therapy by improving EF, maintaining sinus rhythm, and reducing mortality and hospitalization [32]. The Ablation vs Amiodarone for Treatment of Atrial Fibrillation in Patients with Congestive Heart Failure and an Implanted ICD/CRTD (AATAC) showed that catheter ablation of $\mathrm{AF}$ was more successful in maintaining sinus rhythm than amiodarone over 2-year follow-up (HR 2.5, $p<0.001)$. Hospitalization and mortality rates were significantly lower in the ablation group [33]. Subsequently, another study, the AMICA (Atrial fibrillation Management in Congestive heart failure with Ablation) trial, did not reveal any benefit of catheter ablation in patients with $\mathrm{AF}$ and advanced HF [34]. Nevertheless, as cumulative data suggest improved outcomes with ablation of AF in HF patients, most recent recommendations support catheter ablation as first-line treatment for $\mathrm{AF}$ in the right settings [25, 29]. In addition, surgical ablation is highly recommended for patients undergoing another cardiac surgery [35]. Patients with rapid AF refractory to rate control medical ther- 
Table 1. Key clinical trials comparing catheter ablation to other interventions as treatment options for atrial fibrillation in patients with heart failure.

\begin{tabular}{|c|c|c|c|c|c|c|c|c|c|}
\hline Author, year, (trial) & $\begin{array}{l}\text { Sample } \\
\text { size }\end{array}$ & $\begin{array}{l}\text { Age, } \\
\text { years }\end{array}$ & Comparator arm & $\begin{array}{l}\text { Follow-up, } \\
\text { months }\end{array}$ & $\begin{array}{c}\text { Baseline } \\
\text { LVEF, } \\
\%\end{array}$ & $\begin{array}{c}\text { LVEF } \\
\text { increase, \% }\end{array}$ & $\begin{array}{l}\text { LVEF increase } \Delta \\
\text { vs comparator, } \%\end{array}$ & $\begin{array}{c}\text { All-cause } \\
\text { mortality, HR }\end{array}$ & $\begin{array}{c}\text { HF admissions, } \\
\text { HR }\end{array}$ \\
\hline Khan 2008 [39] & 81 & 60 & AV node ablation w/CRT & 6 & 27 & 8 & +9 & NA & NA \\
\hline MacDonald 2011 [40] & 41 & 62 & Medical rate control & 12 & 16 & 4.5 & +1.7 & NA & NA \\
\hline Jones 2013 [41] & 52 & 64 & Medical rate control & 12 & 22 & 11 & +5.5 & NA & NA \\
\hline Hunter 2014 [42] & 366 & 55 & Medical rate control & 20 & 31 & 8.1 & +11.7 & NA & NA \\
\hline Di Biase 2016 [33] & 203 & 62 & Amiodarone & 24 & 29 & 8 & +2.9 & $0.44^{*}$ & $0.55^{*}$ \\
\hline Prabhu 2017 [43] & 68 & 59 & Medical rate control & 6 & 32 & 17 & +7.5 & NA & NA \\
\hline Marrouche 2018 [32] & 363 & 64 & $\begin{array}{l}\text { Medical rate or rhythm } \\
\text { control }\end{array}$ & 38 & 31 & 8 & +7.8 & $0.53^{*}$ & $0.56^{*}$ \\
\hline Kuck 2019 [34] & 140 & 65 & GDMT & 12 & 27 & 8 & -0.3 & NA & NA \\
\hline
\end{tabular}

Abbreviations: AV indicates atrioventricular; GDMT, guideline directed medical treatment; HR, hazard ratio; LVEF, left ventricular ejection fraction; NA, not applicable. ${ }^{*} p$ values $<0.05$.

apy may be offered atrioventricular (AV) node ablation and pacemaker insertion with improved clinical outcomes [36], although the positive effect on mortality is still unproven [37]. The Ablate and Pace for Atrial Fibrillationcardiac resynchronization therapy (APAF-CRT) trial recently showed that AV junction ablation and biventricular pacemaker insertion reduced all-cause mortality compared to rate control therapy (HR $0.26, p=0.004$ ) among patients with permanent AF. The benefit was similar when the EF was lower than 35\% [38]. Table 1 (Ref. [32-34,39-43]) summarizes the main findings of key clinical trials investigating the efficacy of catheter ablation versus other medical or interventional options for treatment of $\mathrm{AF}$ in patients with HF. Collectively, HF and AF often co-exist due to shared risk factors and mutual effects. Treating AF is challenging in HF patients, although successful management may improve outcomes (Fig. 1).

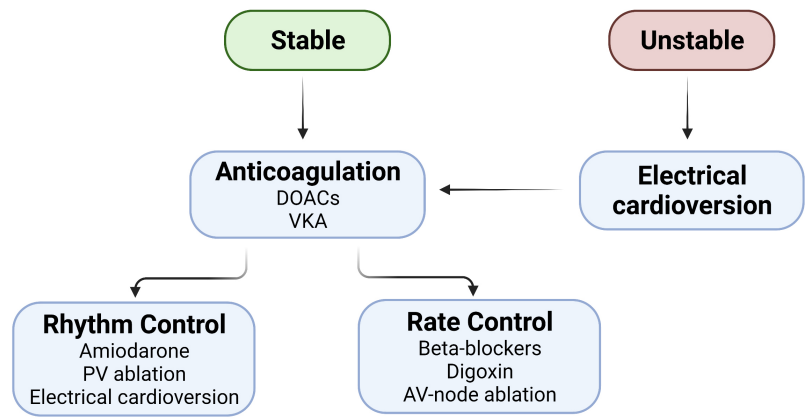

Fig. 1. Recommended management of atrial fibrillation in patients with heart failure and reduced ejection fraction. $\mathrm{AV}$, atrioventricular; DOAC, direct oral anticoagulant; PV, pulmonary veins; VKA, vitamin-K antagonists.

\section{Heart failure with reduced ejection fraction in patients with advanced renal disease}

Patients with concurrent HFrEF and chronic kidney disease (CKD) experience significant morbidity and mortality. The negative effects of CKD on short- and long-term cardiovascular outcomes is more significant as renal disease advances [44,45]. This prognostic effect is amplified by the high prevalence of advanced CKD in patients with HFrEF, where up to $10 \%$ have CKD grades 4-5 and more than 50\% have CKD greater than grade 3 [46-48]. In 2016, the prevalence of CKD and HF in the US was estimated to be 37 million and 6.2 million patients, respectively [49].

Many challenges in treatment of HFrEF-CKD patients stem primarily from cross mechanisms predisposing $\mathrm{HF}$ patients to acute, chronic, or end-stage renal disease, worsening renal function, and hyperkalemia. In addition, the negative impact of CKD on the cardiovascular system eventually leads to increased cardiovascular morbidity and mortality [50].

The heart-kidney crosstalk is best illustrated in the cardiorenal syndrome (CRS), which represents the bidirectional nature of heart-kidney interaction where acute or chronic dysfunction in one organ may provoke acute or chronic dysfunction in the other. Whether CRS is one pathophysiological continuum representing impaired cardiorenal function or different subtypes stemming from specific contributing factors is unknown. However, it is well recognized that several systemic diseases, in addition to neurohormonal, immunologic, inflammatory, and fibrotic effects, may disrupt and bring about various clinical alterations in cardiac and renal function [51-53].

This complex crosstalk between the heart and kidneys poses significant clinical challenges, particularly in patients with underlying HFrEF. These challenges are emphasized when discussing evidence-based therapeutic opportunities for this cohort of patients with HFrEF and advanced CKD 


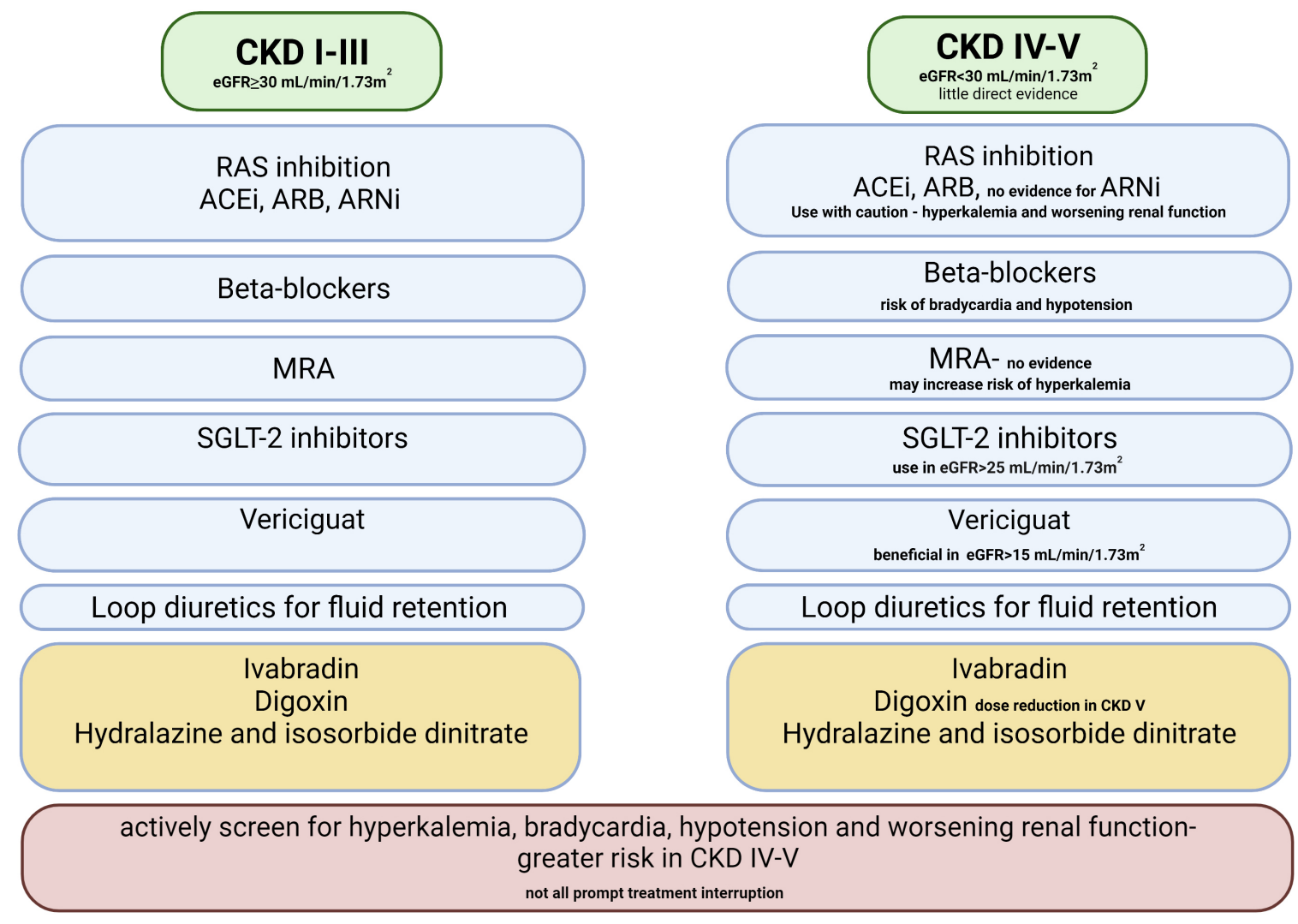

Fig. 2. Management of heart failure with reduced ejection fraction in patients with advanced renal disease. CKD, chronic kidney disease; RAS, renin angiotensin aldosterone; ACEI, angiotensin converting enzyme inhibitors; ARB, angiotensin receptor blocker; ARNI, angiotensin receptor neprilysin inhibitor; MRA, mineralocorticoid receptor antagonist; SGLT-2, sodium-glucose co-transporter 2.

because these patients were markedly underrepresented in most randomized controlled trials, thus leading to sparse guideline-directed medical therapy (GDMT) options left for this high risk population when compared to the general HFrEF population (Fig. 2) [47].

New data regarding the beneficial effects of sodiumglucose cotransporter-2 (SGLT-2) in HFrEF is accumulating, and it has been shown to slow the progression of chronic kidney disease [30,54-56]. The Effect of Sotagliflozin on Cardiovascular Events in Patients with Type 2 Diabetes Post Worsening Heart Failure (SOLOIST-WHF) trial recently investigated the effect of initiation of sotagliflozin upon discharge from an admission related to CHF. Comparing placebo, sotagliflozin reduced the composite outcome of cardiovascular death, hospitalizations and urgent visits for $\mathrm{HF}$ (HR 0.67, $p<0.001$ ), without compromising the renal function [57]. The recently published 2021 ESC guidelines for the diagnosis and treatment of acute and chronic HF recommend quadruple therapy for HFrEF patients, including a beta-blocker, angiotensin receptor-neprilysin inhibitor (ARNi), MRA, and an SGLt-2 inhibitor as first line medical therapy [58,59]. However, generalizability for CKD is lacking, as patients with severe renal dysfunction (estimated glomerular filtration rate (eGFR) $<30 \mathrm{~mL} / \mathrm{min} / 1.73 \mathrm{~m}^{2}$ ) have systematically been excluded from randomized clinical trials. MRA and ARNi may not be safe in patients with advanced CKD due to increased risk of hyperkalemia, and SGLT-2 inhibitor safety has not been examined in patients with eGFR below 20 $\mathrm{mL} / \mathrm{min} / 1.73 \mathrm{~m}^{2}$.

Despite the lack of evidence-based therapies in these patients, some data advocate for RAS inhibition in severe renal dysfunction [60] with reduced risk for renal failure and CV events [61]. A prospective study of the Swedish HF registry supported this, as RAS inhibition in severe CKD was associated with a lower one-year all-cause mortality [62]. PARADIGM-HF (Prospective Comparison of ARNI with ACE inhibition to Determine Impact on Global Mortality and Morbidity in Heart Failure) study, which excluded patients with advanced CKD, found that compared to Enalapril, patients with grade 3 CKD receiving sacubitril/valsartan had a slower rate of decline in eGFR and better $\mathrm{CV}$ outcomes despite a modest increase in proteinuria [63]. Over two decades have passed since MRA's have been shown to decrease morbidity and mortality among patients with severe HF [64]. However, although similar positive $\mathrm{CV}$ outcomes were observed, analysis of the effect of this drug class on patients with CKD has raised concerns of adverse events, notably hyperkalemia [65]. In light of valid safety concerns, current guidelines suggest ex- 
ercising caution when considering MRA treatment in patients with CKD or hyperkalemia [54,55]. Data regarding the effects of Finerenone on patients with type 2 diabetes and advanced CKD have shown lower risks of CKD progression and cardiovascular events than placebo. This effect was enhanced in patients with a history of CV disease $[66,67]$. Finerenone is a novel, nonsteroidal, selective MRA with anti-inflammatory and antifibrotic effects. In the recently published FIGARO-DKD trial, patients with type 2 diabetes mellitus and CKD were treated with finerenone or placebo. Finerenone resulted in a significant reduction in the composite outcome of death from cardiovascular causes, nonfatal myocardial infarction, nonfatal stroke, or hospitalization for HF (HR 0.87, $p=0.003$ ) [68]. In the FIDELIO-DKD trial involving participants with similar characteristics, finerenone significantly decreased the risk of CKD progression (primary outcome) and the risk of death from cardiovascular causes, nonfatal myocardial infarction, nonfatal stroke, or hospitalization for HF (HR $0.86, p=0.03$ ) (secondary outcomes) [66]. It is worth noting that both studies examining the safety and efficacy of finerenone have excluded patients with clinical diagnosis of chronic HFrEF with persistent symptoms (New York Heart Association class II-IV), hence its clinical use in HFrEF and advanced CKD has yet to be determined.

Promising data regarding the use of potassium binders in patients with renal disease receiving RAS inhibitors [69, 70] may enable better GDMT for these patients. However, additional studies are needed to confirm clinical outcomes and long-term effects [71].

Since the 1990 s, the three beta-blocker agents bisoprolol, metoprolol, and carvedilol have been shown to reduce all-cause and cardiovascular mortality, HF hospitalization, and improve functional capacity [72]. Analysis of the MERIT-HF (Metoprolol CR/XL Randomized Intervention Trial in Congestive Heart Failure) [73], CIBIS-II (Cardiac Insufficiency Bisoprolol Study II) [74] and COPERNICUS (Carvedilol Prospective Randomized, Cumulative Survival study) [75] studies suggest beneficial effects of beta-blockade on clinical outcomes among patients with HF and renal disease. However, generalizability is limited due to the fact that few participants with severe renal impairment were included in these studies. Data for a 10year cohort in Taiwan regarding hemodialysis patients receiving beta-blockers for HF demonstrated improved longterm survival among these patients [76]. Whether one beta-blocker is superior to others in hemodialysis patients is unknown; however recent data suggest that both metoprolol and bisoprolol may be associated with lower major adverse cardiovascular event (MACE) and mortality rates [77,78]. Although these data demonstrate a class effect of beta blockers, this potential benefit may be accompanied by risk of bradyarrhythmia and hypotension which should be monitored. The key clinical trials involving patients with significant CKD and relevant outcomes are outlined in Ta- ble 2 (Ref. [56,62,63,65,79-84,87]).

The lack of evidence-based GDMT for comorbid HFrEF-CKD may expose these patients to more common side effects than HFrEF patients without significant CKD. While traditional RAS inhibitors and MRA show positive outcomes, they should be used cautiously as the risk of hyperkalemia could be relatively high. ARNi may provide a better safety profile, but further evaluation is needed. The efficacy of potassium binders is yet to be determined, but these may provide clinical benefits in patients who may benefit from ARNi or MRA but restricted due to hyperkalemia. Although widely used and generally tolerated by comorbid HFrEF-CKD, beta-blockers require careful monitoring for hypotension and bradycardia due to higher risk of developing these sequalae in advanced CKD patients.

\section{Heart failure with reduced ejection fraction in the elderly}

The prevalence of HF increases significantly with age and approximately 18 million patients with $\mathrm{HF}$ are aged $\geq 65$ [86]. Acute decompensated HF is the leading cause of hospitalization among older persons in the United States [87]. The development of life-prolonging therapies for patients with HF and the aging of the general population is expected to increase the burden of HF [88]. The prevalence of $\mathrm{HF}$ in the United States was estimated to rise by $46 \%$ from 2012 to 2030, and an estimate of 2 million octogenarians living with HF in 2030 in the US alone [87].

Evidence-based data regarding HF diagnosis, treatment, and prognosis in this population is lacking [86]. Most HF diagnosis and treatment protocols are extrapolated from studies performed on the younger population. The older population is unique in higher prevalence of comorbidities, physical disabilities, unique medical conditions, and perhaps different responses to treatment.

The cumulative prevalence of chronic diseases increases with age [89]. Most HF patients older than 75 years have multiple cardiovascular and non-cardiovascular comorbidities, such as hypertension, AF, ischemic heart disease, arthritis, diabetes mellitus, CKD, anemia, cancer, severe chronic respiratory disease, and cognitive or psychiatric disorders [90], emphasizing the unique characteristics of this population.

Diagnosis of HF in these patients is challenging because of multiple comorbidities, sedentary lifestyle or physical disabilities that overshadow exertional dyspnea, and cognitive impairment that interferes with proper anamnesis. Diagnosis of HFpEF or cardiac amyloidosis requires a higher index of suspicion since it is more common in this population [91]. In light of these limitations, HF diagnosis in the older population may require greater attention to less specific or atypical symptoms, such as sudden changes in mental status and anorexia. The commonly used natriuretic peptide test for HF diagnosis is less helpful in this population because age and many other comorbidities are 
Table 2. Key clinical studies of class I heart failure therapies in patients with heart failure with reduced ejection fraction and advanced renal disease.

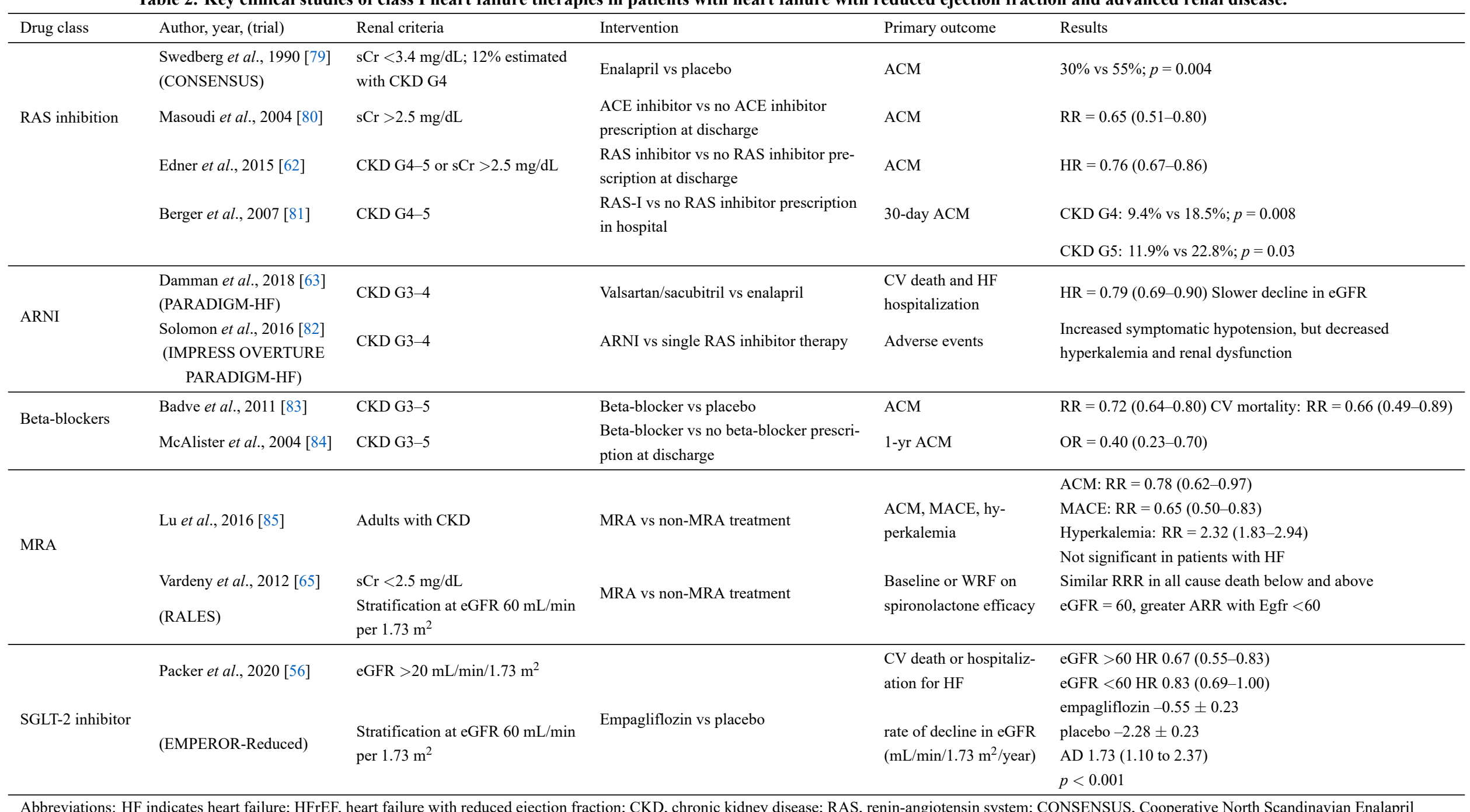

Abbreviations: HF indicates heart failure; HFrEF, heart failure with reduced ejection fraction; CKD, chronic kidney disease; RAS, renin-angiotensin system; CONSENSUS, Cooperative North Scandinavian Enalapril Survival Study; sCR, serum creatinine; ACE, angiotensin converting enzyme; ACM, all-cause mortality; RR, relative risk; HR, hazard ratio; ARNI, angiotensin receptor-neprilysin inhibitor; PARADIGM-HF, Prospective Comparison of ARNI with ACE inhibition to Determine Impact on Global Mortality and Morbidity in Heart Failure; CV, cardiovascular; eGFR, estimated glomerular filtration rate; OR, odds ratio; MACE, major adverse cardiovascular event; MRA, mineralocorticoid receptor antagonist; RALES, Randomized Aldactone Evaluation Study; WRF, worsening renal function; RRR, relative risk reduction; ARR, absolute risk reduction; SGLT-2, sodium glucose cotransporter 2; EMPEROR, Empagliflozin outcome trial in Patients With chronic heart Failure With Reduced Ejection Fraction; AD, absolute difference. 
Table 3. Heart failure treatment considerations in the elderly.

\begin{tabular}{|c|c|c|c|c|}
\hline Drug class & Effects on HF & Treatment considerations & Recommendations & References \\
\hline \multirow{4}{*}{ Beta-blockers } & - $\quad$ Decrease mortality & $\begin{array}{l}\text { - No statistically significant age differ- } \\
\text { ences in mortality reduction }\end{array}$ & $\begin{array}{l}\text { - Initiate at the lowest available dose and up titrate } \\
\text { gradually }\end{array}$ & Rich et al., 2012 [108] \\
\hline & - Preserve myocardial function & $\begin{array}{l}\text { - Older patients are at increased risk for } \\
\text { sinus bradycardia and AV-nodal conduction } \\
\text { disorders }\end{array}$ & - Obtain ECG after initiation and dose escalation & Hernandez et al., 2009 [109] \\
\hline & - $\quad$ Prevent reverse remodeling & & $\begin{array}{l}\text { - Permanent pacemaker should be considered in } \\
\text { symptomatic bradycardia }\end{array}$ & Krum et al., 2006 [110] \\
\hline & $\begin{array}{l}\text { - } \quad \text { Improve beta adrenergic response } \\
\text { - } \quad \text { Reverse adverse effects of neurohor- } \\
\text { monal activation } \\
\text { - } \quad \text { Beneficial effects on mortality and } \\
\text { hospital admissions }\end{array}$ & & & Dulin et al., 2005 [111] \\
\hline \multirow[t]{5}{*}{ RAS inhibitors and ARNi } & $\begin{array}{l}\text { - Decrease mortality, myocardial in- } \\
\text { farction, and hospitalization for HF in pa- } \\
\text { tients with LV dysfunction }\end{array}$ & $\begin{array}{l}\text { Hypotension, hyperkalemia, renal } \\
\text { dysfunction. }\end{array}$ & $\begin{array}{l}\text { - Initiate at the lowest available dose and titrate grad- } \\
\text { ually }\end{array}$ & Flather et al., 2000 [112] \\
\hline & & - $\quad$ Usually manageable with lower doses & - $\quad$ Monitor renal function and serum potassium levels & $\begin{array}{l}\text { ACE inhibitor Myocardial In- } \\
\text { farction Collaborative Group, } \\
1998[113]\end{array}$ \\
\hline & & $\begin{array}{l}\text { - ACEI may cause cough and stress in- } \\
\text { continence, particularly in older women }\end{array}$ & - $\quad$ Target doses as in younger patients & Rich et al., 2012 [108] \\
\hline & & & $\begin{array}{l}\text { - Reduce doses when adverse reactions occur Avoid } \\
\text { in elderly patients with stage IV or stage V CKD who are } \\
\text { not on dialysis }\end{array}$ & Massie et al., 2011 [114] \\
\hline & & & $\begin{array}{l}\text { - Subgroup analysis suggests that ARB can be a better } \\
\text { first line therapy in the elderly }\end{array}$ & Packer et al., 1999 [115] \\
\hline
\end{tabular}


Table 3. Continued.

\begin{tabular}{|c|c|c|c|c|}
\hline Drug class & Effects on $\mathrm{HF}$ & Treatment considerations & Recommendations & References \\
\hline \multirow[t]{2}{*}{ MRA } & $\begin{array}{l}\text { - Decrease mortality and hospitaliza- } \\
\text { tion for } \mathrm{HF} \text { in patients with LV dysfunction }\end{array}$ & Hyperkalemia and renal dysfunction & $\begin{array}{l}\text { - Serum creatinine and potassium level monitoring, } \\
\text { patient education regarding symptoms of hyperkalemic } \\
\text { - } \quad \text { Contraindicated in patients with stage IV or stage V } \\
\text { CKD who are not on dialysis } \\
\text { - Initiate at low doses in older patients with stage III } \\
\text { CKD, increase as tolerated }\end{array}$ & $\begin{array}{l}\text { Juurlink et al., } 2004 \text { [116] } \\
\text { Tamirisa et al., } 2004 \text { [117] } \\
\text { Braunstein et al., } 2007 \text { [118] }\end{array}$ \\
\hline & & & & Pitt et al., 1999 [65] \\
\hline \multirow[t]{4}{*}{ Digoxin } & $\begin{array}{l}\text { - May improve quality of life and re- } \\
\text { duce HF hospitalization, but does not impact } \\
\text { survival }\end{array}$ & $\begin{array}{l}\text { - Digoxin toxicity at lower doses, es- } \\
\text { pecially in older women }\end{array}$ & $\begin{array}{l}\text { - Aim at a therapeutic digoxin serum level of } 0.5-0.9 \\
\mathrm{nmol} / \mathrm{L} \text {. }\end{array}$ & Rich et al., 2001 [119] \\
\hline & & & $\begin{array}{l}\text { - Adjust for renal function and lean body mass, and } \\
\text { monitor closely for electrolyte abnormalities }\end{array}$ & Hanratty et al., 2000 [120] \\
\hline & & & - $\quad$ High index of suspicion for toxicity symptoms & Hauptman et al., 2013 [121] \\
\hline & & & & Ahmed et al., 2006 [122] \\
\hline \multirow[t]{2}{*}{ Vasodilators and nitrates } & $\begin{array}{l}\text { - Improve resting and exercise hemo- } \\
\text { dynamics, exercise capacity, and clinical sta- } \\
\text { tus }\end{array}$ & $\begin{array}{l}\text { - Headache, dizziness, flushing, and } \\
\text { palpitations }\end{array}$ & - Initiate at low doses and increase as tolerated & Leier et al., 1983 [123] \\
\hline & & & $\begin{array}{l}\text { - No evidence for higher rates of adverse reactions in } \\
\text { the older population }\end{array}$ & \\
\hline
\end{tabular}

Abbreviations: HF indicates heart failure; ARNi, angiotensin receptor-neprilysin inhibitor; AV, atrioventricular; ECG, electrocardiogram; RAS, renin angiotensin system; LV, left ventricle; ACEI,

angiotensin converting enzyme inhibitor; $\mathrm{CKD}$, chronic kidney disease; $\mathrm{ARB}$, angiotensin receptor blocker; MRA, mineralocorticoid receptor antagonists. 


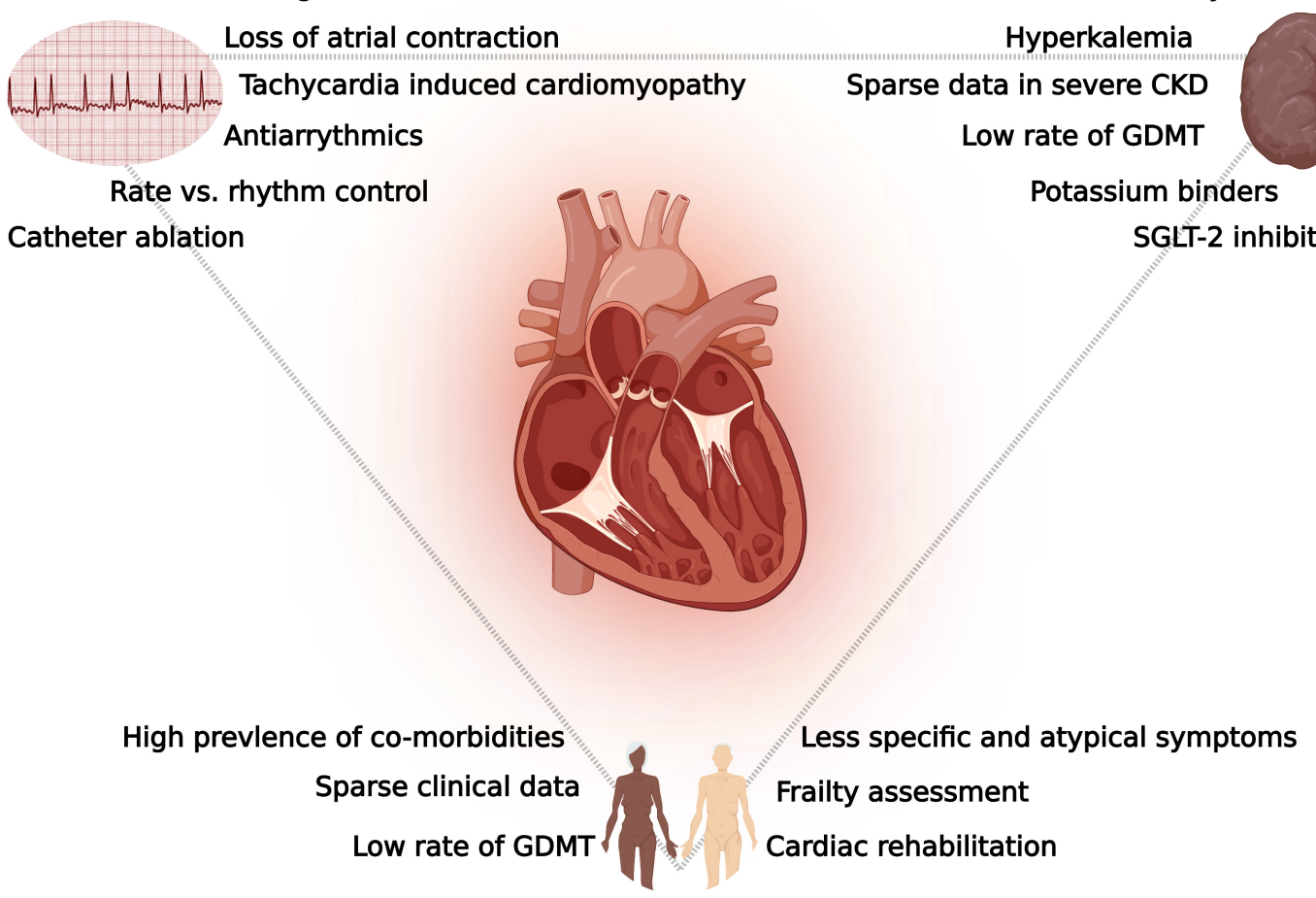

Fig. 3. Key considerations in the management of heart failure with reduced ejection fraction in patients with atrial fibrillation, advanced renal disease and in the aged populations. GDMT, guideline directed medical therapy; CKD, chronic kidney disease; SGLT-2, sodium-glucose co-transporter 2.

associated with elevated serum natriuretic peptide concentrations [92]. Measurement can be beneficial when using higher thresholds for diagnosing or ruling out HF, but overall, the clinician must be aware of atypical symptoms as mentioned above.

HF is a leading cause of disability and mortality in the aged population [93], as baseline physical function in these patients is impaired. The characteristic acute decompensation of HF requires hospitalizations and bed rest, which worsen the baseline disability, and many patients never recover to baseline functions after discharge [94]. Readmission and HF-related hospitalization rates keep rising with age [95]. Geriatric conditions, such as dementia and mobility disorders, are strongly associated with mortality among older patients admitted with worsening HF, both during and after hospitalization [86].

Despite the growing number of aged individuals, HF treatment protocols focusing on the elderly are still sparse. Overall, studies highlight a tendency to under-prescribe recommended treatments [96,97], and lower demand for diagnostic exams, such as echocardiograms in this population [98]. Potential reasons for these findings can be attributed to fear of side effects and comorbidities, focusing on the short-term rather than long-term outcomes, and poor adherence and understanding of physician instructions. The lack of definitive data for a very old population may leave physicians with the belief that the accepted treatments do not include their geriatric patients. It is important to emphasize that all the randomized trials conducted in HFrEF have shown benefit from RAS inhibition and beta-blocker use, regardless of age. Small trials have also demonstrated that these medications improve outcomes, specifically in older HF patients $[93,99]$. Diuretics for maintaining euvolemic status and improving quality of life, as well as the use of nitrates in elderly patients with HF should be used with particular attention to side effects, orthostatic hypotension, and falls [98].

Interventions relevant for older patients are beginning to raise awareness. Frailty is a geriatric syndrome of increased vulnerability to stressors due to cumulative declines across different physiological systems [100]. The prevalence of frailty increases in elderly subjects diagnosed with $\mathrm{HF}$, and the co-occurrence of HF and frailty increases the risk of mortality in patients with HF [101]. It has been shown that moderate or borderline frailty in various medical conditions is responsive to a targeted intervention [102104], making frailty assessments relevant for clinical decisions in patients with HF, and developing specific interventions designed to prevent subsequent disability in frail $\mathrm{HF}$ patients is strongly warranted.

Several studies have investigated the efficacy and safety of various The FRAIL-HF study [105] assessed frailty in older patients with acute decompensated HF and showed prognostic value that was independent of chronic 
comorbidity and acute coexisting diseases. Interventions, such as adapted cardiac rehabilitation, physical exercise, nutrition guidance and HF self-care and treatment optimization could be beneficial to delay the transition from frailty to disability and reduce mortality after discharge in frail patients [106]. In the REHAB-HF (Rehabilitation Therapy in Older Acute Heart Failure patients) trail [107], an early, transitional, tailored, progressive rehabilitation intervention during and after an HF hospitalization in a diverse population of older patients (mean age 72 ) resulted in better outcomes, including physical function, than usual care.

In conclusion, the prevalence of HF continues to increase with age, and HF is one of the leading causes of hospitalization, disability, and mortality in the elderly. This population has unique features that must be evaluated and considered while diagnosing and establishing a treatment plan. Weighing the benefits and risks of treatment in the context of comorbidities requires special attention with avoidance of under-treatment (Table 3, Ref. [65,108-123]). The use of predicting factors to assess prognosis and particular rehabilitation interventions have been shown to improve quality of life as well as long-term outcomes.

\section{Conclusions}

Treatment of HFrEF has evolved dramatically during the past three decades. The benefits of therapy for the general population are gaining evidence with current guidelines suggesting beta-blockers, RAS inhibitors, MRA, SGLT-2 inhibitors as well as other medical and device treatments in specific populations. These therapeutic options have been proven, during these years, to lower hospitalization rates for HF, improve quality of life and reduce mortality. However, some high-risk populations have yet to benefit from the abundance of data. Successful medical treatment or electrophysiological procedures for AF may improve outcomes for these patients. Implementing GDMT in the elderly and patients with advanced CKD while reducing treatment adverse effects related to these comorbidities can improve quality of life and may also have a prognostic impact (Fig. 3). As life expectancy continues to increase, in addition to the prevalence of HF-associated comorbidities, greater emphasis should be made on the establishment of GDMT for the treatment of high-risk populations with HFrEF.

\section{Author contributions}

YK, AK, and RA - conceptualized the review; YK, AK, and RA - wrote the first draft; YK, AK, GP, DN, PA, $\mathrm{AB}$, and $\mathrm{RA}$ - provided critical editing and review. All authors have read and agreed to the published version of the manuscript.

\section{Ethics approval and consent to participate}

Not applicable.

\section{Acknowledgment}

None

\section{Funding}

This research received no external funding.

\section{Conflict of interest}

The authors declare no conflict of interest. Alexandros Briasoulis is serving as one of the Guest editors of this journal. We declare that Alexandros Briasoulis had no involvement in the peer review of this article and has no access to information regarding its peer review. Full responsibility for the editorial process for this article was delegated to Matteo Cameli and Alberto Palazzuoli.

\section{References}

[1] Ponikowski P, Anker SD, AlHabib KF, Cowie MR, Force TL, Hu $\mathrm{S}$, et al. Heart failure: preventing disease and death worldwide. ESC Heart Failure. 2014; 1: 4-25.

[2] Braunwald E. Shattuck lecture-cardiovascular medicine at the turn of the millennium: triumphs, concerns, and opportunities. The New England Journal of Medicine. 1997; 337: 1360-1369.

[3] Borlaug BA, Redfield MM. Diastolic and systolic heart failure are distinct phenotypes within the heart failure spectrum. Circulation. 2011; 123: 2006-13; discussion 2014.

[4] McDonagh TA, Metra M, Adamo M, Gardner RS, Baumbach A, Böhm M, et al. 2021 ESC Guidelines for the diagnosis and treatment of acute and chronic heart failure. European Heart Journal. 2021; 42: 3599-3726.

[5] Roger VL. Epidemiology of Heart Failure. Circulation Research. 2021; 128: 1421-1434.

[6] Liang JJ, Callans DJ. Ablation for Atrial Fibrillation in Heart Failure with Reduced Ejection Fraction. Cardiac Failure Review. 2018; 4: 33-37.

[7] Antlanger M, Aschauer S, Kopecky C, Hecking M, Kovarik J, Werzowa J, et al. Heart Failure with Preserved and Reduced Ejection Fraction in Hemodialysis Patients: Prevalence, Disease Prediction and Prognosis. Kidney and Blood Pressure Research. 2017; 42: 165-176.

[8] Herrera AP, Snipes SA, King DW, Torres-Vigil I, Goldberg DS, Weinberg AD. Disparate inclusion of older adults in clinical trials: priorities and opportunities for policy and practice change. American Journal of Public Health. 2010; 100: S105-S112.

[9] Phillips E, Levine SA. Auricular fibrillation without other evidence of heart disease. The American Journal of Medicine. 1949; 7: 478-489.

[10] Colilla S, Crow A, Petkun W, Singer DE, Simon T, Liu X. Estimates of current and future incidence and prevalence of atrial fibrillation in the U.S. adult population. The American Journal of Cardiology. 2013; 112: 1142-1147.

[11] Mozaffarian D, Benjamin EJ, Go AS, Arnett DK, Blaha MJ, Cushman M, et al. Heart disease and stroke statistics-2015 update: a report from the American Heart Association. Circulation. 2015; 131: e29-322.

[12] Santhanakrishnan R, Wang N, Larson MG, Magnani JW, McManus DD, Lubitz SA, et al. Atrial Fibrillation Begets Heart Failure and Vice Versa: Temporal Associations and Differences in Preserved Versus Reduced Ejection Fraction. Circulation. 2016; 133: 484-492.

[13] Dries DL, Exner DV, Gersh BJ, Domanski MJ, Waclawiw MA, Stevenson LW. Atrial fibrillation is associated with an increased risk for mortality and heart failure progression in patients with 
asymptomatic and symptomatic left ventricular systolic dysfunction: a retrospective analysis of the SOLVD trials. Studies of Left Ventricular Dysfunction. Journal of the American College of Cardiology. 1998; 32: 695-703.

[14] Lubitz SA, Benjamin EJ, Ellinor PT. Atrial fibrillation in congestive heart failure. Heart Failure Clinics. 2010; 6: 187-200.

[15] Maisel WH, Stevenson LW. Atrial fibrillation in heart failure: epidemiology, pathophysiology, and rationale for therapy. The American Journal of Cardiology. 2003; 91: 2D-8D

[16] Li D, Fareh S, Leung TK, Nattel S. Promotion of atrial fibrillation by heart failure in dogs: atrial remodeling of a different sort. Circulation. 1999; 100: 87-95.

[17] Cardin S, Li D, Thorin-Trescases N, Leung T, Thorin E, Nattel S. Evolution of the atrial fibrillation substrate in experimental congestive heart failure: angiotensin-dependent and -independent pathways. Cardiovascular Research. 2003; 60: 315-325.

[18] Schneider MP, Hua TA, Böhm M, Wachtell K, Kjeldsen SE, Schmieder RE. Prevention of atrial fibrillation by ReninAngiotensin system inhibition a meta-analysis. Journal of the American College of Cardiology. 2010; 55: 2299-2307.

[19] Li D, Melnyk P, Feng J, Wang Z, Petrecca K, Shrier A, et al. Effects of experimental heart failure on atrial cellular and ionic electrophysiology. Circulation. 2000; 101: 2631-2638.

[20] Ohtani K, Yutani C, Nagata S, Koretsune Y, Hori M, Kamada T. High prevalence of atrial fibrosis in patients with dilated cardiomyopathy. Journal of the American College of Cardiology. 1995; 25: 1162-1169.

[21] Anter E, Jessup M, Callans DJ. Atrial Fibrillation and Heart Failure. Circulation. 2009; 119: 2516-2525.

[22] Gosselink AT, Crijns HJ, van den Berg MP, van den Broek SA, Hillege H, Landsman ML, et al. Functional capacity before and after cardioversion of atrial fibrillation: a controlled study. British Heart Journal. 1994; 72: 161-166.

[23] Køber L, Swedberg K, McMurray JJV, Pfeffer MA, Velazquez EJ, Diaz R, et al. Previously known and newly diagnosed atrial fibrillation: a major risk indicator after a myocardial infarction complicated by heart failure or left ventricular dysfunction. European Journal of Heart Failure. 2006; 8: 591-598.

[24] Mamas MA, Caldwell JC, Chacko S, Garratt CJ, FathOrdoubadi F, Neyses L. A meta-analysis of the prognostic significance of atrial fibrillation in chronic heart failure. European Journal of Heart Failure. 2009; 11: 676-683.

[25] Gopinathannair R, Chen LY, Chung MK, Cornwell WK, Furie KL, Lakkireddy DR, et al. Managing Atrial Fibrillation in Patients With Heart Failure and Reduced Ejection Fraction: A Scientific Statement From the American Heart Association. Circulation: Arrhythmia and Electrophysiology. 2021; 14: HAE0000000000000078.

[26] Roy D, Talajic M, Nattel S, Wyse DG, Dorian P, Lee KL, et al. Rhythm control versus rate control for atrial fibrillation and heart failure. The New England Journal of Medicine. 2008; 358: 2667-2677.

[27] Lopes RD, Rordorf R, De Ferrari GM, Leonardi S, Thomas L, Wojdyla DM, et al. Digoxin and Mortality in Patients with Atrial Fibrillation. Journal of the American College of Cardiology. 2018; 71: 1063-1074.

[28] Kotecha D, Holmes J, Krum H, Altman DG, Manzano L, Cleland JGF, et al. Efficacy of $\beta$ blockers in patients with heart failure plus atrial fibrillation: an individual-patient data metaanalysis. Lancet. 2014; 384: 2235-2243.

[29] Hindricks G, Potpara T, Dagres N, Arbelo E, Bax JJ, Blomström-Lundqvist C, et al. 2020 ESC Guidelines for the diagnosis and management of atrial fibrillation developed in collaboration with the European Association for Cardio-Thoracic Surgery (EACTS): The Task Force for the diagnosis and management of atrial fibrillation of the European Society of Cardiol- ogy (ESC) Developed with the special contribution of the European Heart Rhythm Association (EHRA) of the ESC. European Heart Journal. 2021; 42: 373-498.

[30] McMurray JJV, Solomon SD, Inzucchi SE, Køber L, Kosiborod MN, Martinez FA, et al. Dapagliflozin in Patients with Heart Failure and Reduced Ejection Fraction. New England Journal of Medicine. 2019; 381: 1995-2008.

[31] Pandey AK, Okaj I, Kaur H, Belley-Cote EP, Wang J, Oraii A, et al. Sodium-Glucose Co-Transporter Inhibitors and Atrial Fibrillation: a Systematic Review and Meta-Analysis of Randomized Controlled Trials. Journal of the American Heart Association. 2021; 10: e 022222.

[32] Marrouche NF, Brachmann J, Andresen D, Siebels J, Boersma L, Jordaens L, et al. Catheter Ablation for Atrial Fibrillation with Heart Failure. New England Journal of Medicine. 2018; 378: 417-427.

[33] Di Biase L, Mohanty P, Mohanty S, Santangeli P, Trivedi C, Lakkireddy D, et al. Ablation Versus Amiodarone for Treatment of Persistent Atrial Fibrillation in Patients with Congestive Heart Failure and an Implanted Device: Results from the AATAC Multicenter Randomized Trial. Circulation. 2016; 133: 1637-1644.

[34] Kuck K, Merkely B, Zahn R, Arentz T, Seidl K, Schlüter M, et al. Catheter Ablation Versus Best Medical Therapy in Patients with Persistent Atrial Fibrillation and Congestive Heart Failure. Circulation: Arrhythmia and Electrophysiology. 2019; 12: $\mathrm{e} 007731$

[35] Calkins H, Hindricks G, Cappato R, Kim Y, Saad EB, Aguinaga L, et al. 2017 HRS/EHRA/ECAS/APHRS/SOLAECE expert consensus statement on catheter and surgical ablation of atrial fibrillation. Heart Rhythm. 2017; 14: e275-e444.

[36] Wood MA, Brown-Mahoney C, Kay GN, Ellenbogen KA. Clinical outcomes after ablation and pacing therapy for atrial fibrillation : a meta-analysis. Circulation. 2000; 101: 1138-1144.

[37] Tan ES, Rienstra M, Wiesfeld ACP, Schoonderwoerd BA, Hobbel HHF, Van Gelder IC. Long-term outcome of the atrioventricular node ablation and pacemaker implantation for symptomatic refractory atrial fibrillation. Europace. 2008; 10: 412-418.

[38] Brignole M, Pentimalli F, Palmisano P, Landolina M, Quartieri $\mathrm{F}$, Occhetta $\mathrm{E}$, et al. AV junction ablation and cardiac resynchronization for patients with permanent atrial fibrillation and narrow QRS: the APAF-CRT mortality trial. European Heart Journal. 2021. (in press)

[39] Khan MN, Jaïs P, Cummings J, Di Biase L, Sanders P, Martin DO, et al. Pulmonary-Vein Isolation for Atrial Fibrillation in Patients with Heart Failure. New England Journal of Medicine. 2008; 359: 1778-1785.

[40] MacDonald MR, Connelly DT, Hawkins NM, Steedman T, Payne J, Shaw M, et al. Radiofrequency ablation for persistent atrial fibrillation in patients with advanced heart failure and severe left ventricular systolic dysfunction: a randomised controlled trial. Heart. 2011; 97: 740-747.

[41] Jones DG, Haldar SK, Hussain W, Sharma R, Francis DP, Rahman-Haley SL, et al. A randomized trial to assess catheter ablation versus rate control in the management of persistent atrial fibrillation in heart failure. Journal of the American College of Cardiology. 2013; 61: 1894-1903.

[42] Hunter RJ, Berriman TJ, Diab I, Kamdar R, Richmond L, Baker $\mathrm{V}$, et al. A randomized controlled trial of catheter ablation versus medical treatment of atrial fibrillation in heart failure (the CAMTAF trial) Circulation. Arrhythmia and Electrophysiology. 2014; 7: 31-38.

[43] Prabhu S, Taylor AJ, Costello BT, Kaye DM, McLellan AJA Voskoboinik A, et al. Catheter Ablation Versus Medical Rate Control in Atrial Fibrillation and Systolic Dysfunction: The CAMERA-MRI Study. Journal of the American College of Car- 
diology. 2017; 70: 1949-1961.

[44] Damman K, Valente MAE, Voors AA, O'Connor CM, van Veldhuisen DJ, Hillege HL. Renal impairment, worsening renal function, and outcome in patients with heart failure: an updated meta-analysis. European Heart Journal. 2013; 35: 455-469.

[45] Smith GL, Lichtman JH, Bracken MB, Shlipak MG, Phillips CO, DiCapua P, et al. Renal Impairment and Outcomes in Heart Failure. Journal of the American College of Cardiology. 2006; 47: 1987-1996.

[46] McAlister FA, Ezekowitz J, Tarantini L, Squire I, Komajda M, Bayes-Genis A, et al. Renal Dysfunction in Patients with Heart Failure with Preserved Versus Reduced Ejection Fraction. Circulation: Heart Failure. 2012; 5: 309-314.

[47] Heywood JT, Fonarow GC, Yancy CW, Albert NM, Curtis AB, Stough WG, et al. Influence of renal function on the use of guideline-recommended therapies for patients with heart failure. The American Journal of Cardiology. 2010; 105: 1140-1146.

[48] Summary of Recommendation Statements. Kidney International Supplements. 2013; 3: 5-14.

[49] Virani SS, Alonso A, Benjamin EJ, Bittencourt MS, Callaway CW, Carson AP, et al. Heart Disease and Stroke Statistics-2020 Update: A Report From the American Heart Association. Circulation. 2020; 141: e139-e596.

[50] Go AS, Chertow GM, Fan D, McCulloch CE, Hsu C. Chronic kidney disease and the risks of death, cardiovascular events, and hospitalization. The New England Journal of Medicine. 2004; 351: 1296-1305.

[51] Damman K, van Deursen VM, Navis G, Voors AA, van Veldhuisen DJ, Hillege HL. Increased Central Venous Pressure is Associated with Impaired Renal Function and Mortality in a Broad Spectrum of Patients with Cardiovascular Disease. Journal of the American College of Cardiology. 2009; 53: 582-588.

[52] Zannad F, Rossignol P. Cardiorenal Syndrome Revisited. Circulation. 2018; 138: 929-944.

[53] Ronco C, Haapio M, House AA, Anavekar N, Bellomo R. Cardiorenal syndrome. Journal of the American College of Cardiology. 2008; 52: 1527-1539.

[54] Yancy CW, Jessup M, Bozkurt B, Butler J, Casey DE, Colvin MM, et al. 2017 ACC/AHA/HFSA Focused Update of the 2013 ACCF/AHA Guideline for the Management of Heart Failure. Journal of the American College of Cardiology. 2017; 70: 776803.

[55] Ponikowski P, Voors AA, Anker SD, Bueno H, Cleland JGF, Coats AJS, et al. 2016 ESC Guidelines for the diagnosis and treatment of acute and chronic heart failure: the Task Force for the diagnosis and treatment of acute and chronic heart failure of the European Society of Cardiology (ESC)Developed with the special contribution of the Heart Failure Association (HFA) of the ESC. European Heart Journal. 2016; 37: 2129-2200.

[56] Packer M, Anker SD, Butler J, Filippatos G, Pocock SJ, Carson $\mathrm{P}$, et al. Cardiovascular and Renal Outcomes with Empagliflozin in Heart Failure. New England Journal of Medicine. 2020; 383: 1413-1424.

[57] Bhatt DL, Szarek M, Steg PG, Cannon CP, Leiter LA, McGuire DK, et al. Sotagliflozin in Patients with Diabetes and Recent Worsening Heart Failure. New England Journal of Medicine. 2021; 384: 117-128.

[58] Seferović PM, Fragasso G, Petrie M, Mullens W, Ferrari R, Thum T, et al. Heart Failure Association of the European Society of Cardiology update on sodium-glucose co-transporter 2 inhibitors in heart failure. European Journal of Heart Failure. 2020; 22: 1984-1986.

[59] McDonagh TA, Metra M, Adamo M, Gardner RS, Baumbach A, Böhm M, et al. 2021 ESC Guidelines for the diagnosis and treatment of acute and chronic heart failure: Developed by the Task Force for the diagnosis and treatment of acute and chronic heart failure of the European Society of Cardiology (ESC) With the special contribution of the Heart Failure Association (HFA) of the ESC. European Heart Journal. 2021. (in press)

[60] Hein AM, Scialla JJ, Edmonston D, Cooper LB, DeVore AD, Mentz RJ. Medical Management of Heart Failure with Reduced Ejection Fraction in Patients with Advanced Renal Disease. JACC: Heart Failure. 2019; 7: 371-382.

[61] Xie X, Liu Y, Perkovic V, Li X, Ninomiya T, Hou W, et al. Renin-Angiotensin System Inhibitors and Kidney and Cardiovascular Outcomes in Patients with CKD: a Bayesian Network Meta-analysis of Randomized Clinical Trials. American Journal of Kidney Diseases. 2016; 67: 728-741.

[62] Edner M, Benson L, Dahlström U, Lund LH. Association between renin-angiotensin system antagonist use and mortality in heart failure with severe renal insufficiency: a prospective propensity score-matched cohort study. European Heart Journal. 2015; 36: 2318-2326.

[63] Damman K, Gori M, Claggett B, Jhund PS, Senni M, Lefkowitz MP, et al. Renal Effects and Associated Outcomes during Angiotensin-Neprilysin Inhibition in Heart Failure. JACC. Heart Failure. 2018; 6: 489-498.

[64] Pitt B, Zannad F, Remme WJ, Cody R, Castaigne A, Perez A, et al. The Effect of Spironolactone on Morbidity and Mortality in Patients with Severe Heart Failure. New England Journal of Medicine. 1999; 341: 709-717.

[65] Vardeny O, Wu DH, Desai A, Rossignol P, Zannad F, Pitt B, et al. Influence of Baseline and Worsening Renal Function on Efficacy of Spironolactone in Patients with Severe Heart Failure. Journal of the American College of Cardiology. 2012; 60: 2082-2089.

[66] Bakris GL, Agarwal R, Anker SD, Pitt B, Ruilope LM, Rossing $\mathrm{P}$, et al. Effect of Finerenone on Chronic Kidney Disease Outcomes in Type 2 Diabetes. New England Journal of Medicine. 2020; 383: 2219-2229.

[67] Pitt B, Kober L, Ponikowski P, Gheorghiade M, Filippatos G, Krum $\mathrm{H}$, et al. Safety and tolerability of the novel non-steroidal mineralocorticoid receptor antagonist BAY 94-8862 in patients with chronic heart failure and mild or moderate chronic kidney disease: a randomized, double-blind trial. European Heart Journal. 2013; 34: 2453-2463.

[68] Pitt B, Filippatos G, Agarwal R, Anker SD, Bakris GL, Rossing $\mathrm{P}$, et al. Cardiovascular Events with Finerenone in Kidney Disease and Type 2 Diabetes. The New England Journal of Medicine. 2021. (in press)

[69] Packham DK, Rasmussen HS, Lavin PT, El-Shahawy MA, Roger SD, Block G, et al. Sodium zirconium cyclosilicate in hyperkalemia. The New England Journal of Medicine. 2014; 372: 222-231.

[70] Weir MR, Bakris GL, Bushinsky DA, Mayo MR, Garza D, Stasiv Y, et al. Patiromer in patients with kidney disease and hyperkalemia receiving RAAS inhibitors. The New England Journal of Medicine. 2014; 372: 211-221.

[71] Natale P, Palmer SC, Ruospo M, Saglimbene VM, Strippoli GFM. Potassium binders for chronic hyperkalaemia in people with chronic kidney disease. Cochrane Database of Systematic Reviews. 2020; 6: CD013165.

[72] Funck-Brentano C. Beta-blockade in CHF: from contraindication to indication. European Heart Journal Supplements. 2006; 8: C19-C27.

[73] Ghali JK, Wikstrand J, Van Veldhuisen DJ, Fagerberg B, Goldstein $\mathrm{S}$, Hjalmarson A, et al. The Influence of Renal Function on Clinical Outcome and Response to $\beta$-Blockade in Systolic Heart Failure: Insights from Metoprolol CR/XL Randomized Intervention Trial in Chronic HF (MERIT-HF). Journal of Cardiac Failure. 2009; 15: 310-318.

[74] Castagno D, Jhund PS, McMurray JJV, Lewsey JD, Erdmann E, Zannad F, et al. Improved survival with bisoprolol in patients 
with heart failure and renal impairment: an analysis of the cardiac insufficiency bisoprolol study II (CIBIS-II) trial. European Journal of Heart Failure. 2010; 12: 607-616.

[75] Wali RK, Iyengar M, Beck GJ, Chartyan DM, Chonchol M, Lukas MA, et al. Efficacy and Safety of Carvedilol in Treatment of Heart Failure with Chronic Kidney Disease. Circulation: Heart Failure. 2011; 4: 18-26.

[76] Tang C, Wang C, Chen T, Hong C, Sue Y. Prognostic Benefits of Carvedilol, Bisoprolol, and Metoprolol Controlled Release/Extended Release in Hemodialysis Patients with Heart Failure: a 10-Year Cohort. Journal of the American Heart Association. 2016; 5: e002584.

[77] Wu P, Lin Y, Liu J, Tsai Y, Kuo M, Chiu Y, et al. Comparative effectiveness of bisoprolol and carvedilol among patients receiving maintenance hemodialysis. Clinical Kidney Journal. 2021; 14: 983-990.

[78] Assimon MM, Brookhart MA, Fine JP, Heiss G, Layton JB, Flythe JE. A Comparative Study of Carvedilol Versus Metoprolol Initiation and 1-Year Mortality among Individuals Receiving Maintenance Hemodialysis. American Journal of Kidney Diseases. 2018; 72: 337-348.

[79] Swedberg K, Eneroth P, Kjekshus J, Snapinn S. Effects of enalapril and neuroendocrine activation on prognosis in severe congestive heart failure (follow-up of the CONSENSUS trial). The American Journal of Cardiology. 1990; 66: D40-D45.

[80] Masoudi FA, Rathore SS, Wang Y, Havranek EP, Curtis JP, Foody JM, et al. National patterns of use and effectiveness of angiotensin-converting enzyme inhibitors in older patients with heart failure and left ventricular systolic dysfunction. Circulation. 2004; 110: 724-731.

[81] Berger AK, Duval S, Manske C, Vazquez G, Barber C, Miller L, et al. Angiotensin-converting enzyme inhibitors and angiotensin receptor blockers in patients with congestive heart failure and chronic kidney disease. American Heart Journal. 2007; 153: 1064-1073.

[82] Solomon SD, Claggett B, McMurray JJV, Hernandez AF, Fonarow GC. Combined neprilysin and renin-angiotensin system inhibition in heart failure with reduced ejection fraction: a meta-analysis. European Journal of Heart Failure. 2016; 18: 1238-1243.

[83] Badve SV, Roberts MA, Hawley CM, Cass A, Garg AX, Krum $\mathrm{H}$, et al. Effects of beta-adrenergic antagonists in patients with chronic kidney disease: a systematic review and meta-analysis. Journal of the American College of Cardiology. 2011; 58: 11521161.

[84] McAlister FA, Ezekowitz J, Tonelli M, Armstrong PW. Renal insufficiency and heart failure: prognostic and therapeutic implications from a prospective cohort study. Circulation. 2004; 109: 1004-1009.

[85] Lu R, Zhang Y, Zhu X, Fan Z, Zhu S, Cui M, et al. Effects of mineralocorticoid receptor antagonists on left ventricular mass in chronic kidney disease patients: a systematic review and meta-analysis. International Urology and Nephrology. 2016; 48: 1499-1509.

[86] Chaudhry SI, Wang Y, Gill TM, Krumholz HM. Geriatric conditions and subsequent mortality in older patients with heart failure. Journal of the American College of Cardiology. 2010; 55: 309-316.

[87] Heidenreich PA, Albert NM, Allen LA, Bluemke DA, Butler J, Fonarow GC, et al. Forecasting the impact of heart failure in the United States: a policy statement from the American Heart Association. Circulation. Heart Failure. 2013; 6: 606-619.

[88] Virani SS, Alonso A, Aparicio HJ, Benjamin EJ, Bittencourt MS, Callaway CW, et al. Heart Disease and Stroke Statistics2021 Update: A Report From the American Heart Association. Circulation. 2021; 143: e254-e743.
[89] Stenholm S, Westerlund H, Head J, Hyde M, Kawachi I, Pentti J, et al. Comorbidity and functional trajectories from midlife to old age: the Health and Retirement Study. The Journals of Gerontology. Series a, Biological Sciences and Medical Sciences. 2014; 70: $332-338$.

[90] Hanon O, Belmin J, Benetos A, Chassagne P, De Decker L, Jeandel $\mathrm{C}$, et al. Consensus of experts from the French Society of Geriatrics and Gerontology on the management of heart failure in very old subjects. Archives of Cardiovascular Diseases. 2021; 114: 246-259.

[91] Arora S, Patil NS, Strassle PD, Qamar A, Vaduganathan M, Fatima A, et al. Amyloidosis and 30-Day Outcomes among Patients with Heart Failure. JACC: CardioOncology. 2020; 2: 710-718

[92] Plichart M, Orvoën G, Jourdain P, Quinquis L, Coste J, Escande $\mathrm{M}$, et al. Brain natriuretic peptide usefulness in very elderly dyspnoeic patients: the BED study. European Journal of Heart Failure. 2017 ; 19: 540-548.

[93] Komajda M, Hanon O, Hochadel M, Lopez-Sendon JL, Follath F, Ponikowski P, et al. Contemporary management of octogenarians hospitalized for heart failure in Europe: Euro Heart Failure Survey II. European Heart Journal. 2008; 30: 478-486.

[94] Warraich HJ, Kitzman DW, Whellan DJ, Duncan PW, Mentz RJ, Pastva AM, et al. Physical Function, Frailty, Cognition, Depression, and Quality of Life in Hospitalized Adults $\geq 60$ Years with Acute Decompensated Heart Failure with Preserved Versus Reduced Ejection Fraction. Circulation: Heart Failure. 2018; 11: e005254

[95] Tuppin P, Cuerq A, de Peretti C, Fagot-Campagna A, Danchin N, Juillière $\mathrm{Y}$, et al. First hospitalization for heart failure in France in 2009: patient characteristics and 30-day follow-up. Archives of Cardiovascular Diseases. 2013; 106: 570-585.

[96] Foebel AD, Heckman GA, Hirdes JP, Tyas SL, Tjam EY, McKelvie RS, et al. Clinical, Demographic and Functional Characteristics Associated with Pharmacotherapy for Heart Failure in Older Home Care Clients. Drugs \& Aging. 2011; 28: 561-573.

[97] Mann JL, Evans TS. A review of the management of heart failure in long-term care residents. The Consultant Pharmacist. 2006; 21: 222-228.

[98] Boully C, Vidal J, Guibert E, Ghazali FN, Pesce A, Beauplet $\mathrm{B}$, et al. National survey on the management of heart failure in individuals over 80 years of age in French geriatric care units. BMC Geriatrics. 2019; 19: 204.

[99] Komajda M, Hanon O, Hochadel M, Follath F, Swedberg K, Gitt $\mathrm{A}$, et al. Management of octogenarians hospitalized for heart failure in Euro Heart Failure Survey i. European Heart Journal. 2007; 28: 1310-1318.

[100] Fried LP, Tangen CM, Walston J, Newman AB, Hirsch C, Gottdiener J, et al. Frailty in older adults: evidence for a phenotype. The Journals of Gerontology. Series a, Biological Sciences and Medical Sciences. 2001; 56: M146-M156.

[101] Pandey A, Kitzman D, Whellan DJ, Duncan PW, Mentz RJ, Pastva AM, et al. Frailty among Older Decompensated Heart Failure Patients. JACC: Heart Failure. 2019; 7: 1079-1088.

[102] Gill TM, Baker DI, Gottschalk M, Peduzzi PN, Allore H, Byers A. A program to prevent functional decline in physically frail, elderly persons who live at home. The New England Journal of Medicine. 2002; 347: 1068-1074.

[103] Hoogeboom TJ, Dronkers JJ, van den Ende CHM, Oosting E, van Meeteren NLU. Preoperative therapeutic exercise in frail elderly scheduled for total hip replacement: a randomized pilot trial. Clinical Rehabilitation. 2010; 24: 901-910.

[104] Carli F, Awasthi R, Gillis C, Kassouf W. Optimizing a frail elderly patient for radical cystectomy with a prehabilitation program. Canadian Urological Association Journal. 2014; 8: E884E887. 
[105] Vidán MT, Blaya-Novakova V, Sánchez E, Ortiz J, SerraRexach JA, Bueno H. Prevalence and prognostic impact of frailty and its components in non-dependent elderly patients with heart failure. European Journal of Heart Failure. 2016; 18: 869875 .

[106] Bakker FC, Robben SHM, Olde Rikkert MGM. Effects of hospital-wide interventions to improve care for frail older inpatients: a systematic review. BMJ Quality \& Safety. 2011; 20: 680-691.

[107] Kitzman DW, Whellan DJ, Duncan P, Pastva AM, Mentz RJ, Reeves GR, et al. Physical Rehabilitation for Older Patients Hospitalized for Heart Failure. New England Journal of Medicine. 2021; 385: 203-216.

[108] Rich MW. Pharmacotherapy of heart failure in the elderly: adverse events. Heart Failure Reviews. 2012; 17: 589-595.

[109] Hernandez AF, Hammill BG, O’Connor CM, Schulman KA, Curtis LH, Fonarow GC. Clinical effectiveness of beta-blockers in heart failure: findings from the OPTIMIZE-HF (Organized Program to Initiate Lifesaving Treatment in Hospitalized Patients with Heart Failure) Registry. Journal of the American College of Cardiology. 2009; 53: 184-192.

[110] Krum H, Hill J, Fruhwald F, Sharpe C, Abraham G, Zhu J, et al. Tolerability of beta-blockers in elderly patients with chronic heart failure: the COLA II study. European Journal of Heart Failure. 2006; 8: 302-307.

[111] Dulin BR, Haas SJ, Abraham WT, Krum H. Do elderly systolic heart failure patients benefit from beta blockers to the same extent as the non-elderly? Meta-analysis of $>12,000$ patients in large-scale clinical trials. The American Journal of Cardiology. 2005; 95: 896-898.

[112] Flather MD, Yusuf S, Køber L, Pfeffer M, Hall A, Murray G, et al. Long-term ACE-inhibitor therapy in patients with heart failure or left-ventricular dysfunction: a systematic overview of data from individual patients. The Lancet. 2000; 355: 15751581.

[113] Indications for ACE inhibitors in the early treatment of acute myocardial infarction: systematic overview of individual data from 100,000 patients in randomized trials. ACE Inhibitor Myocardial Infarction Collaborative Group. Circulation. 1998; 97:
2202-2212.

[114] Massie BM, Armstrong PW, Cleland JG, Horowitz JD, Packer M, Poole-Wilson PA, et al. Toleration of high doses of angiotensin-converting enzyme inhibitors in patients with chronic heart failure: results from the ATLAS trial. The Assessment of Treatment with Lisinopril and Survival. Archives of Internal Medicine. 2001; 161: 165-171.

[115] Packer M, Poole-Wilson PA, Armstrong PW, Cleland JG, Horowitz JD, Massie BM, et al. Comparative effects of low and high doses of the angiotensin-converting enzyme inhibitor, lisinopril, on morbidity and mortality in chronic heart failure. ATLAS Study Group. Circulation. 1999; 100: 2312-2318.

[116] Juurlink DN, Mamdani MM, Lee DS, Kopp A, Austin PC, Laupacis A, et al. Rates of hyperkalemia after publication of the Randomized Aldactone Evaluation Study. The New England Journal of Medicine. 2004; 351: 543-551.

[117] Tamirisa KP, Aaronson KD, Koelling TM. Spironolactoneinduced renal insufficiency and hyperkalemia in patients with heart failure. American Heart Journal. 2004; 148: 971-978.

[118] Braunstein GD. Clinical practice. Gynecomastia. The New England Journal of Medicine. 2007; 357: 1229-1237.

[119] Rich MW, McSherry F, Williford WO, Yusuf S. Effect of age on mortality, hospitalizations and response to digoxin in patients with heart failure: the DIG study. Journal of the American College of Cardiology. 2001; 38: 806-813.

[120] Hanratty CG, McGlinchey P, Johnston GD, Passmore AP. Differential pharmacokinetics of digoxin in elderly patients. Drugs \& Aging. 2000; 17: 353-362.

[121] Hauptman PJ, McCann P, Romero JMR, Mayo M. Reference laboratory values for digoxin following publication of Digitalis Investigation Group (DIG) trial data. JAMA Internal Medicine. 2013; 173: 1552-1554.

[122] Ahmed A, Rich MW, Love TE, Lloyd-Jones DM, Aban IB, Colucci WS, et al. Digoxin and reduction in mortality and hospitalization in heart failure: a comprehensive post hoc analysis of the DIG trial. European Heart Journal. 2006; 27: 178-186.

[123] Leier CV, Huss P, Magorien RD, Unverferth DV. Improved exercise capacity and differing arterial and venous tolerance during chronic isosorbide dinitrate therapy for congestive heart failure. Circulation. 1983; 67: 817-822. 